\title{
A CASE OF SARCOMA OF THE TEMPORAL BONE.*
}

\author{
BY CHARLES J. IKIPP, M. D., NEWARIK, N. J.
}

C. H., 5 years of age, was brought to the Newark Eye and Ear Infirmary on account of pain in and a swelling back of his ears, on Marcl I6, I900. Accorrling to the father's statements the boy had had at no time before the present attack pain in or a clischarge from his ears He had measles some time ago, but no ear symptoms were noticed at the time. About a month before he came to the Infirmary he began to complain of pain in his ear. His mother syringed the ear, but dicl not consult a physician about it. About a week ago a feshy mass was first seen in the cxternal meatus and this has steaclily increased in size since then. He has had great pain in his ear for several weeks. I found the external meatus completely filled by a fleshy mass, in appearance like an ordinary polypus. Pressure on the ear catused offensive purulent fluid to come out of the meatus. As I was about to leave the hospital when the boy was brought in, and the boy. was in great pain, I concluded to remove the polypus at once, as I thought that it caused retention of pus in the ear and to postpone further procedure till next day. I had-no difficulty in removing with a snare the growth which seemed to spring from the lower wall, close to the membrana tympani The removal of the growth was followed by considerable bleeding, which stopped, however, on plugging the external canal. The operation was not followed by relief of the pain in the ear. This ear was apparently totally deaf. Tuning forks placed on median line were heard best in the deaf ear. On the following day, while he was under the influence of ether, I made a careful exploration and found a large hole in the lower wall of the osseus canal, close to the tympanic membrane; from this hole a probe could be passed downward and inward, and on withdrawing the probe much purulent fluid escaped from the hole. The region of the mastoid was swollen, but not red, and for some distance below the auricle the soft parts felt boggy. No clistinct fluctuation could be detected. No enlarged lymphatic glands could be felt anywhere near the auricle. The drum membrane was of a deep red color and swollen and a small perforation was found in the posterior half. There was nothing in the appearance of the ear or the surrounding parts which aroused

* Read before the thirty-fifth annual meeting of the American Otological Society, New London, Conn., July 15, 1002. 
a suspicion that the case was anything other than an ordinary otitis media purulenta with extension of the disease to the mastoid, and I therefore proceeded in the usual way to open the antrum. On making the incision from below upward through the soft part, the knife at once opened a large cavity below and in front of the apex of the mastoid. This cavity was full of granulations of large size, some of them as large as a small pea, and of a greenish color. I removed a considerable quantity of them with a spoon and put them aside for microscopic examination, but they were unfortunately thrown away by one of the nurses before the operation was finished. This cavity extended far in toward the pharynx. The cortex of the mastoid was quite soft and so was the posterior upper and lower wall of the external canal. I was able to remove all of the softened bone with a sharp spoon and by the time I had gotten through curetting, but little of the posterior upper and lower walls of the external canal remained, the antrum and the tympanum were one cavity; the hammer and the incus were removed with forceps, and the tympanum cleaned of granulations. I do not remember ever to have had another case in which the bone was so soft and could be scraped away with so little force. The cavity was packed in the usual way and the boy put to bed. Temperature was $102^{\circ}$ before the operation, but fell to about $100^{\circ}$ after the operation and remained at this point during the following two weeks. Nothing noteworthy occurred during the first month after the operation, except an unusually rapid and very profuse growth of granulation from every part of the wound. We tried firm packing, cauterization with nitrate of silver and the galvanic cautery, but with little effect. In the beginning of May the whole cavity was filled with a fleshy mass and by the fifteenth of this month this mass had grown at least half an inch above the level of the outer plate of the bone. On the I6th of May I put the boy once more under the influence of ether and removed all of the mass and also all softened bone with sharp spoons and gouges. The operation was not followed by unpleasant reaction, but the fleshy masses soon sprouted again from all parts of the cavity and grew so luxuriantly that they protruded again above the level of the bone in about two weeks. The boy's temperature was never over IOI $^{\circ}$ during this time, and most of the time it was about normal. About the first of June he began to complain of heaclache and pain in his ear and nothing but the free use of morphine allayed the pain. Paralysis of the facial nerve followed a few days later, and the ophthalmoscope, which had been frequently used for the examination of the eyes since he first came 
under observation, now showed a beginning optic neuritis in both eyes. He lost flesh quite rapidly while the tumor steadily increased in size. I did not attempt to remove the growth again, but sent the boy home, where he died about three months later. The tumor removed after death weighed 6 pounds 8 ounces and measured 25 inches in circumference. No autopsy was made. This photograph was taken in July, about two months before his death .

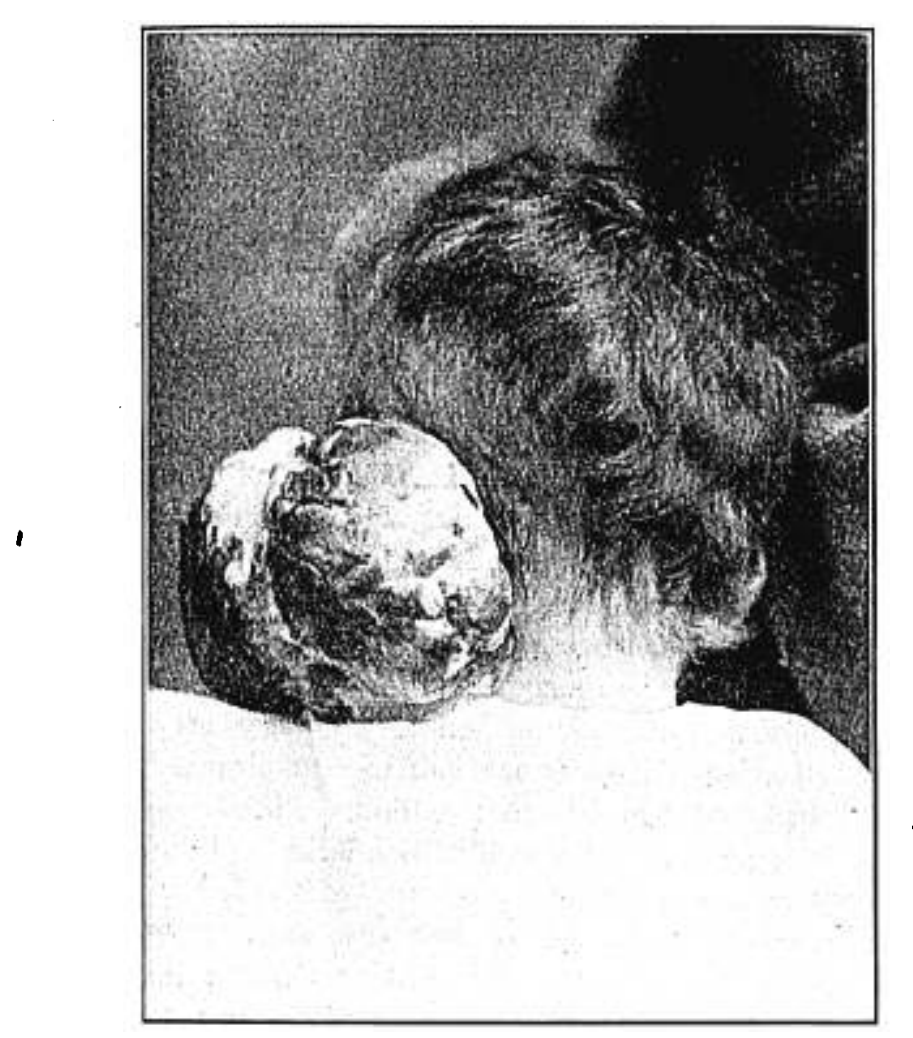

I have seen and operated on several other cases presenting about the same clinical features, but in all of them the disease, so far as I know, did not return in any. one of them. The microscopical examination of the masses removed at the first operation was very unsatisfactory, I could not positively say that the bits of tissue examined 
were characteristic of a sarcoma, but consisted of small round 'cells with but little intercellular tissue. The masses removed at the second operation left no cloubt as to the sarcomatous character.

I was struck at the first operation with the peculiar greenish color and the large size of the granulations contained in the cavity in the soft parts beneath and in front of the mastoid. They were so entirely different in appearance from anything that I had previously seen in connection with mastoid clisense that I called the attention of my assistants to them at the time. I regret exceedingly that they were lost. The very soft condition of the bone was another feature that attracted my attention at the time, but in all other respects, the case was like most other cases of mastoid disease due to purulent middle ear inflammation and suspicion of the malignant character of the disease was not aroused till the very rapid growth of the mass was noticed some weeks after the first operation.

I am indebted to Dr: W. A. Condict, of Dover, N. J., who treated the boy after his discharge from the hospital, for the history of the case subsequent to his discharge from the Infirmary. 